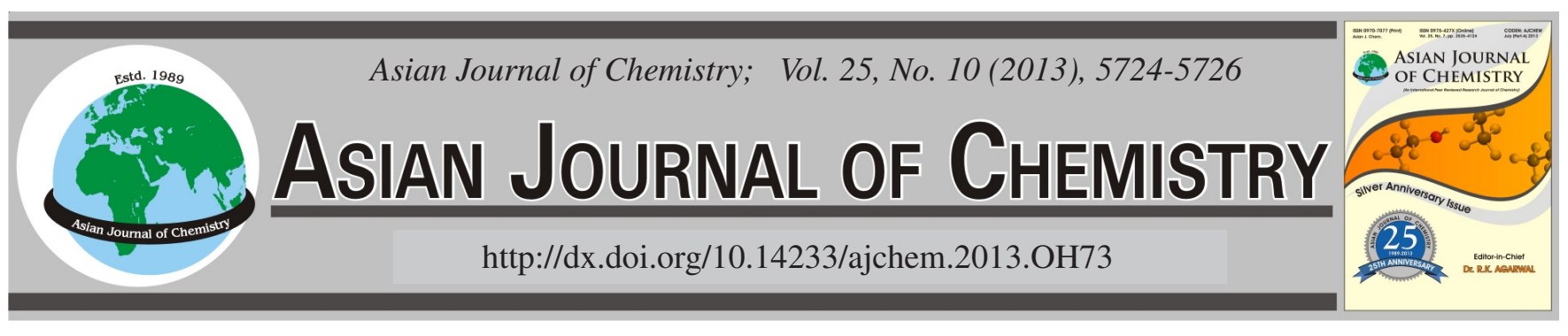

\title{
Scientometric Analysis of Multifunctional Flux Cored Welding Wire $\dagger$
}

\author{
HwAN-TAE KIM and SANG-CHEOL KIL ${ }^{*}$
}

Korea Institute of Science and Technology Information, 66 Hoegi-ro, Dongdaemun-gu, Seoul 130-741, Republic of Korea

*Corresponding author: Fax: +82 2 32996028; E-mail: kilsc@kisti.re.kr

\begin{abstract}
The flux cored arc welding which uses a tubular electrode containing a flux rather than a solid electrode and which is a type of semi-automatic arc welding process is widely used in the welding of ships, offshore structures, steel structural building. As flux cored arc welding in the modern industries is placing stringent demands on the manufacturing techniques and performance requirements, the multifunctional flux cored welding wires with high quality and efficiency are developed for the production of good welds and this has led to an increasing attention in the development of multifunctional flux cored welding wires. This paper covers the scientometric analysis of the multifunctional flux cored welding wires which is based on the published research works in the 'flux cored welding wires' obtained from the Korea Institute of Science and Technology Information's database, Web of Science System and deals with the details of the background data of the flux cored welding wire technology.
\end{abstract}

Key Words: Multifunctional flux cored welding wire, Flux cored arc welding, Scientometric analysis, Methologist, Source of data.

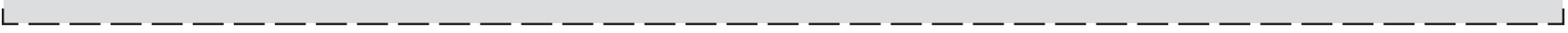

\section{INTRODUCTION}

Flux cored arc welding uses a wire which contains a flux materials in its core that when burned by the heat of the arc, produce shielding gases and fluxing agents to help produce a sound welds ${ }^{1,2}$. Fig. 1 shows the schematic diagrams of the multifunctional flux cored welding wire which contains flux consisted of the various compositions including the metal powders in the tubular electrode ${ }^{3}$. While the shielded metal arc welding with covered electrodes has been widely used in steel structures in out-of-position welding, the flux cored welding wire makes flux cored arc welding the ideal choice for welding requirements. The increasing usage of flux cored welding wire in high strength steel structures is attributed to the advantages over covered electrodes in the aspect of weld metal high quality as well as operational efficiency of high deposition rate especially in the vertical-up position ${ }^{4}$. The flux cored arc welding process is most suited for application with thicker materials.

The purpose of this paper is to investigate the research trends of multifunctional flux cored welding wires by the scientometric techniques ${ }^{5}$ which are being used for several purpose in science like evaluation of scientific output by analyzing author collaboration, output of publication, authorship pattern, institutions contribution, etc..

\section{EXPERIMENTAL}

The scientometric analysis of the multifunctional flux cored welding wire is based on the published research works (including the contents of those papers which are mainly con- sisted with experimental and theoretical papers) in the 'flux cored welding wire' obtained from the KISTI's database, Web of Science System and deals with the details of the background data of the multifunctional flux cored welding wire technology. The data's were searched through the bibliographic search flow chart (Fig. 2).

\section{RESULTS AND DISCUSSION}

During 1986-2012, a total of 114 papers were published in the field of flux cored welding wire and the trend of the volume of annually published papers is shown in Fig. 3. It is observed that the highest number of papers has produced in 2011 (13 records).

More than 20 countries were connected with the research in the field of flux cored welding wire and Fig. 4 shows the number of the published papers by top ten countries. It is observed that following China (21) on the list were Korea (16), USA (13), India (9) and Brazil (9).

Fig. 5 shows the index level of the published papers (over 3 papers) by country. Index level can be defined by eqn. (1).

$$
\mathrm{Q}=\mathrm{N} / \mathrm{M}
$$

where $\mathrm{Q}$ means index level. $\mathrm{M}$ is number of average citations for total papers published in certain technical area, multifunctional flux cored welding wire in this paper; $\mathrm{N}$ is the number of average cited published papers of certain country. It is observed that following Slovenia (2.6) on the list were Germany (2.0), Japan (1.8), India (1.6) and USA (1.5). 

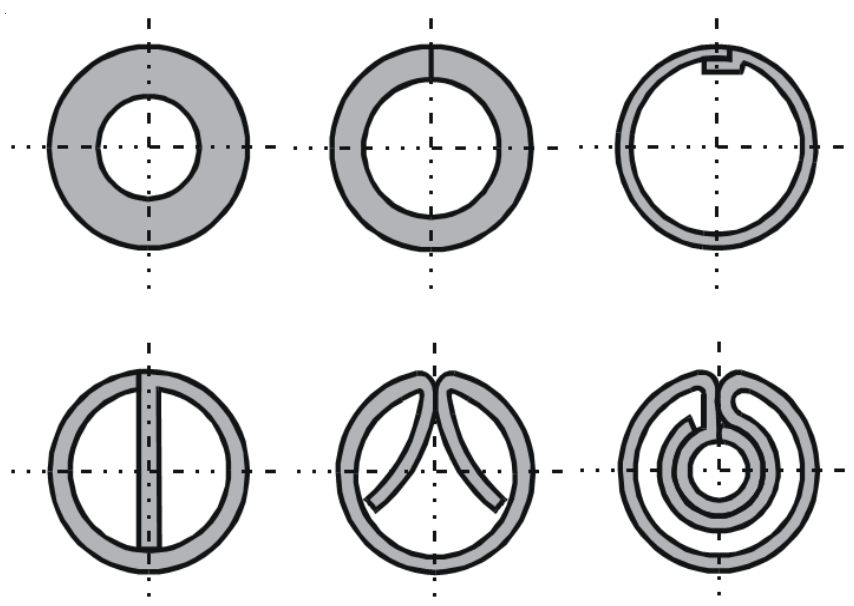

Fig. 1. Schematic diagrams of the flux cored welding wire ${ }^{3}$

Web of Science SM

Science Citation Index Expanded is a multidisciplinary index to the journal literature of the sciences. It fully indexes over 7100 major journals across 150 scientific disciplines and includes all cited references captured from indexed articles

Database Coverage: 1899 to present

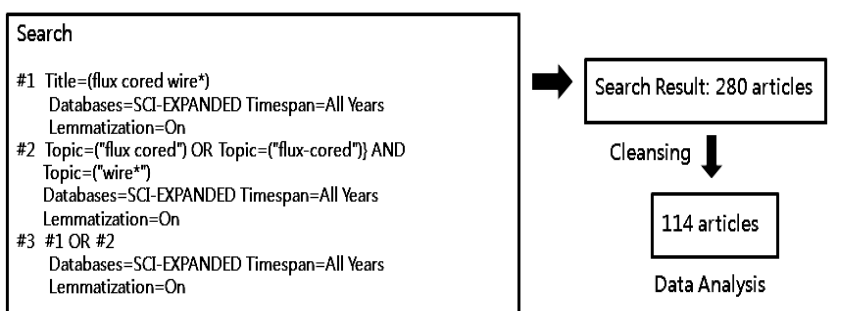

Fig. 2. Bibliographic search flow chart of flux cored welding wire

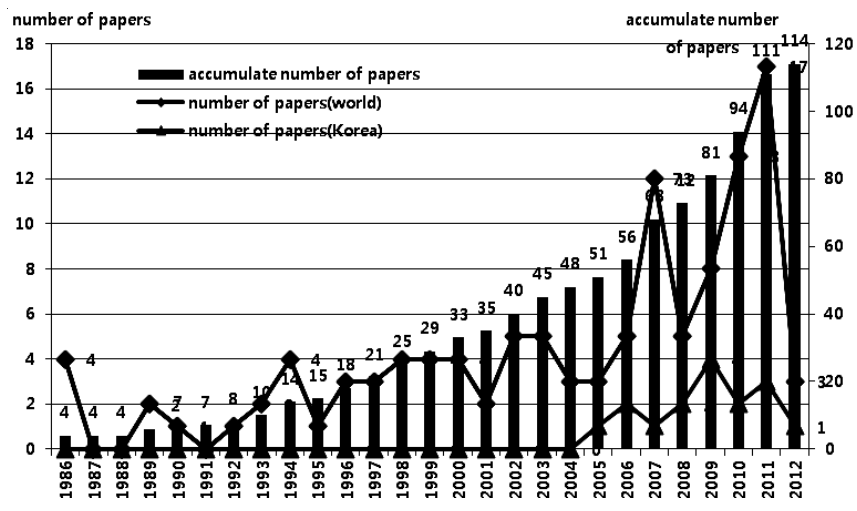

Fig. 3. Annual trend of the published papers in flux cored welding wire (year)
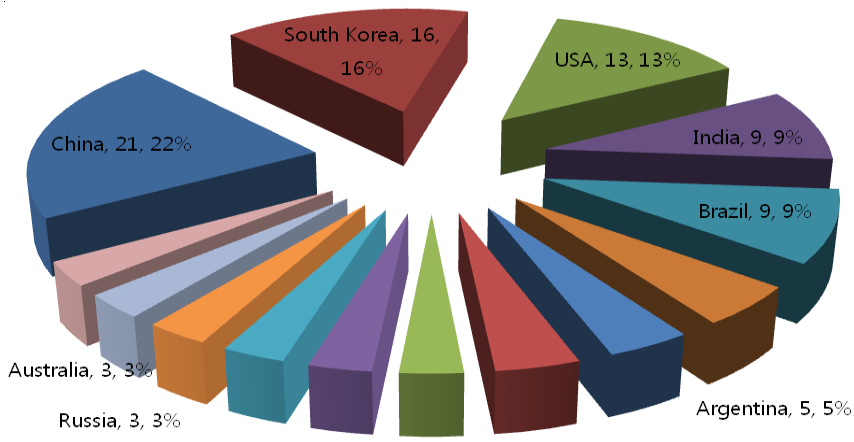

Taiwan, 3, 3\% UK, 3, 3\% Cuba, 3, 3\% Germany, 3, 3\% Japan, 4, 4\% Slovenia, 4, 4\%

Fig. 4. Comparison of the published papers in flux cored welding wire (country)

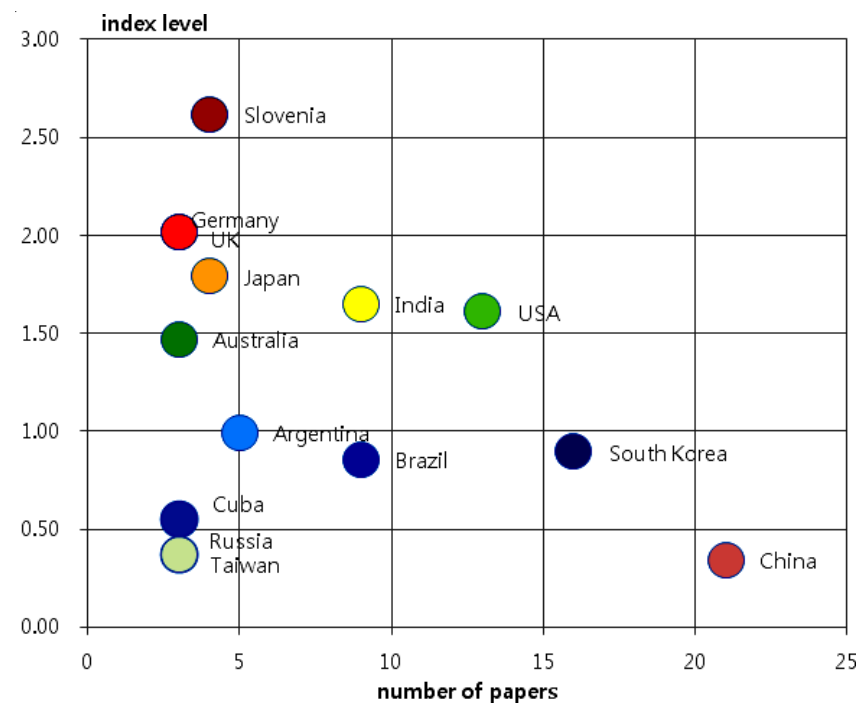

Fig. 5. Index level/number of the published papers (country)

Table-1 provides a list of the relation index of international collaboration and strength of international collaboration (institute). It is analyzed the Dong A University has got first place in the published papers (7), Colourado School of Mines in the citation per paper (4.33), University of Ljubljana in the index label of Institute (3.30), University of Estadual Campinas in the relation index of international collaboration $(0.75)$ and University of Oriente in the strength of international collaboration (7.6), respectively.

\section{TABLE-1}

RELATION INDEX OF INTERNATIONAL COLLABORATION/STRENGTH OF INTERNATIONAL COLLABORATION(INSTITUTE)

\begin{tabular}{lccccc}
\hline Institute & $\mathrm{N}^{*}$ & $\mathrm{CPP}^{* * *}$ & $\mathrm{Q}^{* * * *}$ & $\mathrm{~S}^{* * * * *}$ & $\mathrm{~L}^{* * * * * *}$ \\
\hline Dong A University & 7 & 2.14 & 1.18 & 0 & 0 \\
University of Estadual Campinas & 4 & 1.25 & 0.69 & 0.75 & 5.7 \\
Pusan National University & 4 & 0.75 & 0.41 & 0 & 0 \\
Xian Univ. Architecture \& Technol. & 3 & 1 & 0.55 & 0 & 0 \\
Harbin Institute Technology & 3 & 0 & 0 & 0 & 0 \\
Jiangsu University & 3 & 0 & 0 & 0 & 0 \\
Beijing University of Technology & 3 & 0 & 0 & 0 & 0 \\
Pukyong National University & 3 & 1 & 0.55 & 0.33 & 2.53 \\
Colourado School of Mines & 3 & 4.33 & 2.39 & 0.67 & 5.07 \\
University of Ljubljana & 3 & 6 & 3.30 & 0 & 0 \\
Korea Institute of Indu. Technol. & 3 & 1.33 & 0.73 & 0 & 0 \\
University of Oriente & 3 & 1 & 0.55 & 1 & 7.6 \\
University of Buenos Aires & 3 & 1 & 0.55 & 0 & 0 \\
\hline N: Nur
\end{tabular}

${ }^{*} \mathrm{~N}$ : Number of papers; ${ }^{* *} \mathrm{CPP}$ : Citation per paper; ${ }^{* * *} \mathrm{Q}$ : Index label of Institute; ${ }^{* * * *} \mathrm{~S}$ : Relation index of international collaboration; ${ }^{* * * * *} \mathrm{~L}$ : Strength of international collaboration

Summary: Investigation was carried out to study the research trends of the multifunctional flux cored welding wire by performance of scientometric analysis. The study shows the trend of the volume of annually published papers, the number of the published papers by country, the index level of the published papers by country, the number of collaborated countries/number of the published papers, the relation index of international collaboration and strength of international collaboration (institute). The application of the advanced flux cored welding wire will depend on the weldment quality 
features required for ships, offshore structures, steel structural building, such as weld properties, automation and operation cost.

\section{ACKNOWLEDGEMENTS}

This research was supported by the ReSEAT(Retired Scientists and Engineers for Advancement of Technology) Program of KISTI (Korea Institute of Science and Technology Information) through the NRF (National Research Foundation of Korea) funded by the MEST (Ministry of Education, Science and Technology).

\section{REFERENCES}

1. M. Shibahara, K. Yamaguchi, T. Onda, S. Ito and K. Masaoka, Quart. J. Japan Weld. Soc., 27, 154 (2009).

2. Dennis Crockett, Weld. J., 91, 51 (2012).

3. Winkler, Welding Processes and Equipment, EWE-1/1.11 2002 SLV Duisburg, p. 5.

4. J.E. Ramirez, Weld. J., 87, 65 (2008).

5. S. Raja and R. Balasubramani, Eur. J. Sci. Res., 56, 294 (2011). 